\title{
GRAPHICAL EXPRESSION OF THERMODYNAMIC CHARACTERISTICS OF ABSORPTION PROCESS IN AMMONIA-WATER SYSTEM
}

\author{
Jiří POSPÍŠIL ${ }^{1}$ and Zdeněk FORTELNÝ ${ }^{2}$
}

\begin{abstract}
The adiabatic sorption is very interesting phenomenon that occurs when vapor of refrigerant is in contact with unsaturated liquid absorbent-refrigerant mixture and exchange of heat is forbid between the system and an environment. This contribution introduces new auxiliary lines that enable correct position determination of the adiabatic sorption process in the $p-T-x$ diagram of ammoniawater system. The presented auxiliary lines were obtained from common functions for fast calculation of water-ammonia system properties. Absorption cycles designers often utilize p-t-x diagrams of working mixtures for first suggestion of new absorption cycles. The $p-t-x$ diagrams enable fast correct determination of saturate states of liquid (and gaseous) mixtures of refrigerants and absorbents. The working mixture isn't only at saturated state during a real working cycle. If we know pressure and temperature of an unsaturated mixture, exact position determination is possible in the $p$-t-x diagrams too.
\end{abstract}

\section{INTRODUCTION}

Absorption cycles represent thermally driven cycles for wide variety of utilizing. Intensive development of the absorption cycles has led to significant increasing of the coefficient of performance (COP) in last 20 years. The most important way of COP increasing is based on reutilizing of sensitive heat of working mixtures. Another possible way for increasing of COP is based on reutilization of absorption heat generated during absorption of refrigerant vapor in unsaturated mixture. The generator-absorber heat exchange (GAX) cycles utilize this phenomenon. Heat generated during an absorption process is used for a desorption process in a generator.

The absorption heat is important parameter of up to date absorption cycles. Good utilizing of the absorption heat can be reached only if absorption cycle designers have correct detail information about an absorption process. Absorption cycle designers often utilize $p-t-x$ diagrams of working mixtures for first suggestion of new absorption cycles. The $\mathrm{p}-\mathrm{t}-\mathrm{x}$ diagrams enable fast correct determination of saturate states of liquid (and gaseous) mixtures of refrigerants and absorbents. The $\mathrm{p}-\mathrm{t}-\mathrm{x}$ diagrams serve as basic instrument for absorption cycle designing. But these diagrams don't enable to obtain detail information about adiabatic sorption process.

This paper presents the new auxiliary lines for improving of this situation. The auxiliary lines base from common functions for fast calculation of water-ammonia system

\footnotetext{
${ }^{1}$ Jiří Pospíšil, Vysoké učení technické v Brně, Fakulta strojního inženýrství, pospisil.j@fme.vutbr.cz

${ }^{2}$ Zdeněk Fortelný, Vysoké učení technické v Brně, Fakulta stroj. inž., yforte00@stud.fme.vutbr.cz
} 
properties. The new auxiliary lines enable correct position determination of the adiabatic sorption process in the $\mathrm{p}-\mathrm{t}-\mathrm{x}$ diagram of an ammonia-water system.

\section{Mathematical description}

The adiabatic sorption is useful phenomenon that occurs during contact of refrigerant vapor and an unsaturated liquid absorbent-refrigerant mixture. Exchange of heat is forbidden between the mixture and an environment. The unsaturated mixture is absorbing the refrigerant vapor and the mixture temperature increase. This process continues until the saturated state is reached. Mathematic description of this process is based on conservation of energy. That is realized by utilizing of conservation of enthalpy during isobaric absorption. The schema at fig. 1 shows considered inlets and outlet of the process.

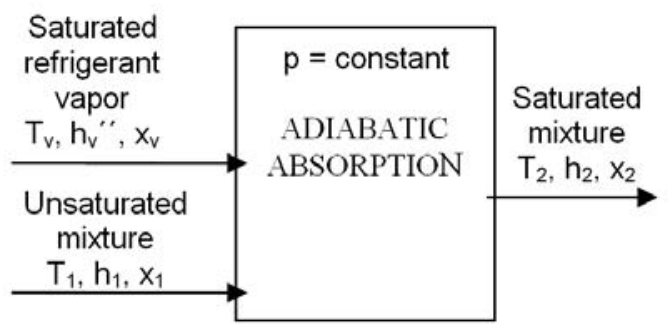

Figure 1 Inlets and outlets of the adiabatic absorption process

Where $T, h, x$ mean temperature, enthalpy and mole fraction of NH3. Subscripts $v, 1,2$ identify properties of saturated refrigerant vapor, unsaturated mixture and saturated mixture. Mole fraction of $\mathrm{NH} 3$ in saturated refrigerant vapor is equal to $100 \%$. Corresponding enthalpy and temperature is calculated from equations obtained from [1]. Saturated mixture parameters were calculated with utilizing of the functions for fast calculation of water-ammonia system properties [1] [2] [3].

Mole concentration and temperature of unsaturated mixture is required together with absorption pressure as input parameters. The functions for fast calculation of mixture properties provide information only for saturated state of the mixture. So, we must use an appropriate approach for determination of unsaturated mixture specific enthalpy. At this paper we used knowledge of specific thermal capacity of the saturated mixture and temperature of the saturated mixture. Unsaturated liquid mixture enthalpy h1 was calculated with utilizing of equation (1).

$$
h_{1}=h_{1}^{\prime}-c_{p 1}^{\prime} \cdot\left(T_{1}^{\prime}-T_{1}\right)
$$

Where superscript ' denotes saturated state of liquid mixture and subscript 1 denotes liquid mixture with mole fraction of $\mathrm{NH} 3$ equal to mole fraction of the original liquid unsaturated mixture. Pressure is assumed at constant level.

Equations for calculation of the saturated mixture specific thermal capacity, temperature of the saturated mixture and the saturated mixture specific enthalpy are depended only on actual pressure and $\mathrm{NH} 3$ mass concentration.

$$
\begin{aligned}
& T_{1}^{\prime}=f\left(p, x_{1}\right) \\
& h_{1}{ }^{\prime}=f\left(T_{1}^{\prime}, x_{1}\right)
\end{aligned}
$$




$$
c_{p 1}^{\prime}=f\left(T_{1}^{\prime}, x_{1}\right)
$$

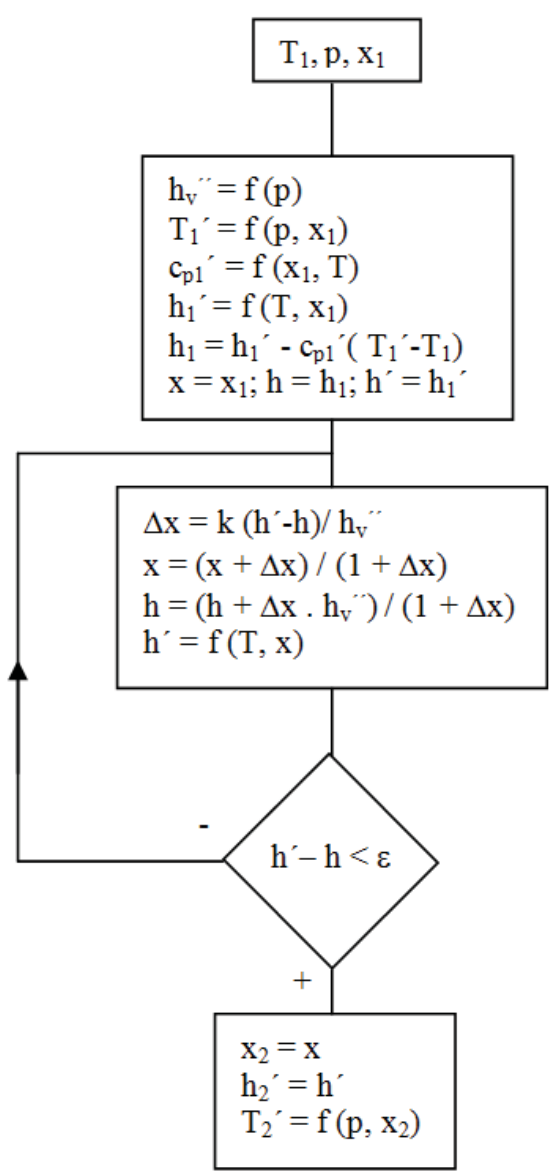

Figure 2 Iterativ calculation of adiabatic sorption saturate state

After calculation of the mentioned equations, we compare value of enthalpy of the unsaturated liquid mixture and the saturated liquid mixture with same mole fraction of $\mathrm{NH3}$. If enthalpy of the unsaturated mixture is below enthalpy value of the saturated one, the absorption of $\mathrm{NH} 3$ vapor continues. Mass concentration of $\mathrm{NH} 3$ is slightly increased in following step and calculation starts with this increased concentration of $\mathrm{NH} 3$. Calculation becomes repetitive. It is useful to engage iterative calculation process, see fig.2.

Variables without subscript correspond to state of the liquid mixture during the saturation process. During this process, temperature, enthalpy and mass fraction of $\mathrm{NH} 3$ increase until a terminal saturated state denoted by subscript 2 . The iterative calculation is stopped in the instance when a difference between enthalpy of the saturated mixture and enthalpy of the unsaturated mixture is smaller then a convergence criterion $\varepsilon$.

The used equations and appropriate parameters are mentioned in the following section. First, the equation for calculation of saturated liquid mixture temperature is written as function of pressure and mole fraction of $\mathrm{NH} 3[1]$ :

$$
T^{\prime}=T_{0} \sum_{i} a_{i}(1-x)^{m i}\left[\ln \left(\frac{p_{0}}{p}\right)\right]^{n_{i}}
$$




\begin{tabular}{cccc}
\hline $\mathrm{i}$ & $\mathrm{m}_{\mathrm{i}}$ & $\mathrm{n}_{\mathrm{i}}$ & $\mathrm{a}_{\mathrm{i}}$ \\
\hline \hline 1 & 0 & 0 & $0,322302 \times 10^{1}$ \\
2 & 0 & 1 & $-0,384206 \times 10^{0}$ \\
3 & 0 & 2 & $0,460965 \times 10^{-1}$ \\
4 & 0 & 3 & $-0,378945 \times 10^{-2}$ \\
5 & 0 & 4 & $0,135610 \times 10^{-3}$ \\
6 & 1 & 0 & $0,487755 \times 10^{0}$ \\
7 & 1 & 1 & $-0,120108 \times 10^{0}$ \\
8 & 1 & 2 & $0,106154 \times 10^{-1}$ \\
9 & 2 & 3 & $-0,533589 \times 10^{-3}$ \\
10 & 4 & 0 & $0,785041 \times 10^{1}$ \\
11 & 5 & 0 & $-0,115941 \times 10^{2}$ \\
12 & 5 & 1 & $-0,523150 \times 10^{-1}$ \\
13 & 6 & 0 & $0,489596 \times 10^{1}$ \\
14 & 13 & 1 & $0,421059 \times 10^{-1}$ \\
\hline \hline
\end{tabular}

Table 1 List of parameters for equitation (5)

Enthalpy of the saturated liquid mixture was calculated from equation [1]:

$$
h^{\prime}=h_{0} \sum_{i} a_{i}\left(\frac{T}{T_{0}}-1\right)^{m_{i}} x^{n_{i}}
$$

\begin{tabular}{cccc}
\hline $\mathrm{i}$ & $\mathrm{m}_{\mathrm{i}}$ & $\mathrm{n}_{\mathrm{i}}$ & $\mathrm{a}_{\mathrm{i}}$ \\
\hline 1 & 0 & 1 & $-0,761080 \times 10^{1}$ \\
2 & 0 & 4 & $0,256905 \times 10^{2}$ \\
3 & 0 & 8 & $-0,247092 \times 10^{3}$ \\
4 & 0 & 9 & $+0,325952 \times 10^{3}$ \\
5 & 0 & 12 & $-0,158854 \times 10^{3}$ \\
6 & 0 & 14 & $0,619084 \times 10^{2}$ \\
7 & 1 & 0 & $0,114314 \times 10^{2}$ \\
8 & 1 & 1 & $0,118157 \times 10^{1}$ \\
9 & 2 & 1 & $0,284179 \times 10^{1}$ \\
10 & 3 & 3 & $0,741609 \times 10^{1}$ \\
11 & 5 & 3 & $0,891844 \times 10^{3}$ \\
12 & 5 & 4 & $-0,161309 \times 10^{4}$ \\
13 & 5 & 5 & $0,622106 \times 10^{3}$ \\
14 & 6 & 2 & $-0,207588 \times 10^{3}$ \\
15 & 6 & 4 & $-0,687393 \times 10^{1}$ \\
16 & 8 & 0 & $0,350716 \times 10^{1}$ \\
\hline $\mathrm{h}_{0}=100 \mathrm{~kJ} / \mathrm{kg}$ & & & $\mathrm{T}_{0}=273,16 \mathrm{~K}$ \\
\hline
\end{tabular}

Table 2 List of parameters for equitation (6)

Specific thermal capacity [2] of the saturated liquid mixture was calculated with utilizing of following equations:

$$
\begin{aligned}
& c_{p}^{\prime}=x \cdot c_{p_{\mathrm{HH}_{3}}^{\prime}}^{\prime}+(1-x) \cdot c_{p_{\mathrm{H}_{2} \mathrm{O}}^{\prime}}^{\prime} \\
& c_{p_{i}}^{\prime}=A_{c p}+B_{c p} \cdot \tau^{-1} \\
& \tau \equiv 1-\frac{T^{\prime}}{T_{c r i t}}
\end{aligned}
$$




\begin{tabular}{ccc}
\hline & $\mathrm{A}_{\mathrm{cp}}$ & $\mathrm{B}_{\mathrm{cp}}$ \\
\hline $\mathrm{NH}_{3}$ & 3,875648 & 0,242125 \\
\hline $\mathrm{H}_{2} \mathrm{O}$ & 3,665785 & 0,236312 \\
\hline
\end{tabular}

Table 3 List of parameters for equitation (8)

The solution critical temperature [3] was calculated with utilizing of equation:

$$
T_{c r i t}=\sum_{i} a_{i} x^{i}
$$

\begin{tabular}{cc}
\hline $\mathrm{i}$ & $\mathrm{a}_{\mathrm{i}}$ \\
\hline 0 & 647,14 \\
\hline 1 & $-199,822371$ \\
\hline 2 & 109,035522 \\
\hline 3 & $-239,626217$ \\
\hline 4 & 88,689691 \\
\hline
\end{tabular}

Table 4 List of parameters for equitation (10)

\section{AUXILIARY LINES FORMING}

Now we can start to draw the adiabatic absorption process in the $p$-t-x diagram. The unsaturated mixture is labeled as position 1 in fig.3. We assume the isobaric absorption process so saturating solution locations must stay on a horizontal line. Concentration of $\mathrm{NH} 3$ and temperature of the solution rise during the absorption process. The terminal state of the solution is shifted in right hand direction from the initial position.

The final mixture parameters are easy to calculate with the equations mentioned above. Very useful is to have opportunity of obtaining the parameters directly from the p-t-x diagram. This is useful for time saving during designing of new cycles.

When we have been looking for new adiabatic absorption auxiliary lines, we summarized what parameters are required for determination of the saturate state position. Necessary input parameters are mole fraction of $\mathrm{NH} 3$, temperature of the unsaturated state and corresponding pressure. The pressure and the temperature serve for determination of the initial state position in the $\mathrm{p}$-t-x diagram.

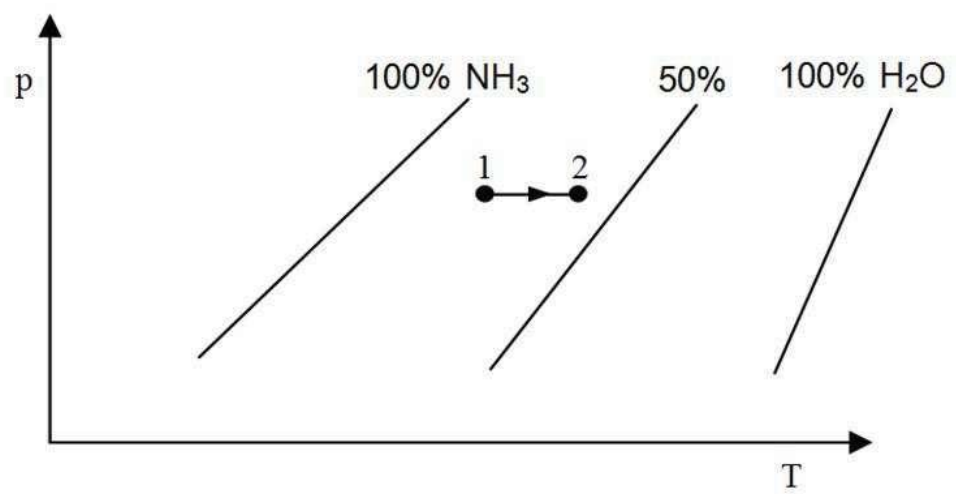

Figure 3 Adiabatic absorption process in p-t-x diagram 
Since, concentration lines are drawn only for saturated states in the p-t-x diagram, position of the unsaturated solution is always located on left hand side from the saturated solution concentration line drawn for same mole fraction of $\mathrm{NH} 3$ as the unsaturated solution mole fraction. This saturated solution concentration line enables to estimate how far is the unsaturated solution from its saturated state.

Two basic points define an adiabatic absorption auxiliary line in $\mathrm{p}-\mathrm{T}$ diagram. First point corresponds to position of the unsaturated mixture - point 1. Second point lies on corresponding saturated mixture concentration line bellow position of the terminal saturated state of mixture - point 2 (obtained from calculation), see fig. 4.

The adiabatic absorption auxiliary lines show linear character in p-t diagram of ammonia - water system. This character was verified by series of calculations. All adiabatic absorption auxiliary lines are parallel in $\mathrm{p}-\mathrm{T}$ diagram. A schema of $\mathrm{p}$-t-x diagram with an adiabatic absorption auxiliary line is shown in fig.4. The auxiliary line utilizes the position of an intersection with the saturate solution concentration line for determination of a terminal saturated solution position.

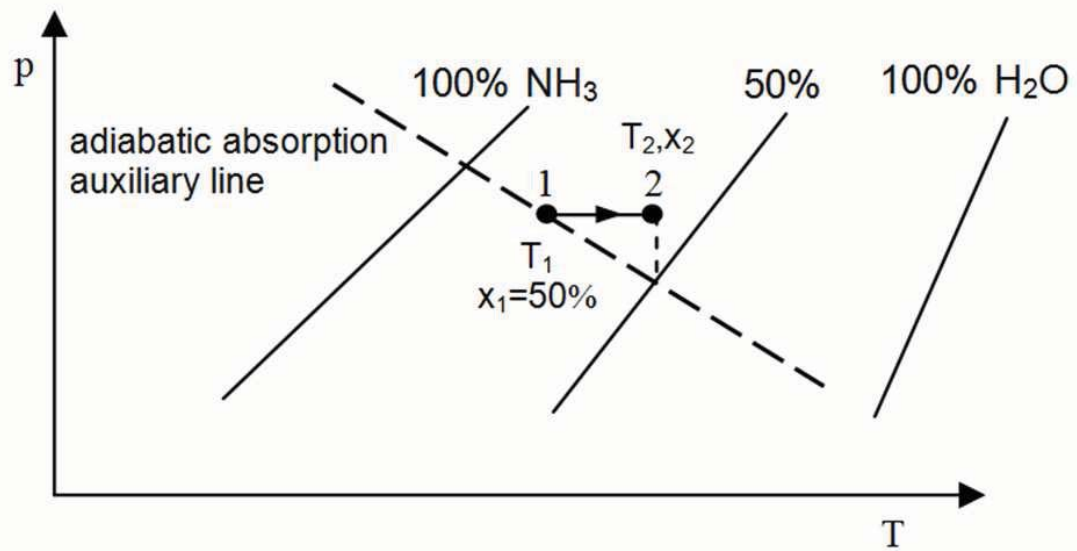

Figure 4 Adiabatic absorption auxiliary line in p-t-x diagram

Position of the saturated liquid can be obtained in four following steps with utilizing of an adiabatic absorption auxiliary line:

1. Draw the adiabatic absorption auxiliary line crossing the initial unsaturated solution (known $\mathrm{p}, \mathrm{T}, \mathrm{x}$ ).

2. Determine an intersecting position of the adiabatic absorption auxiliary line and the saturate solution concentration line for same concentration as concentration of the initial unsaturated solution.

3. Draw a vertical line upward from the intersection.

4. The terminal saturated solution is located in an intersection of the vertical line and a corresponding isobaric line (pressure of initial unsaturated solution).

A final $p$-t-x diagram of ammonia-water system with four adiabatic absorption auxiliary lines is shown in fig.5. An example of using of the adiabatic absorption auxiliary lines is drawn in this figure too. The auxiliary lines are linear for mole fraction of $\mathrm{NH} 3$ from $100 \%$ till $10 \%$. Under $10 \%$ the auxiliary lines divert from linear character. The auxiliary lines are not drawn for mole fractions under $10 \%$ in the fig.5. Because it is not clear if this 
behavior results from mixture physical parameters or inaccuracy of the used equations. Detail analysis of this behavior will provide following research.

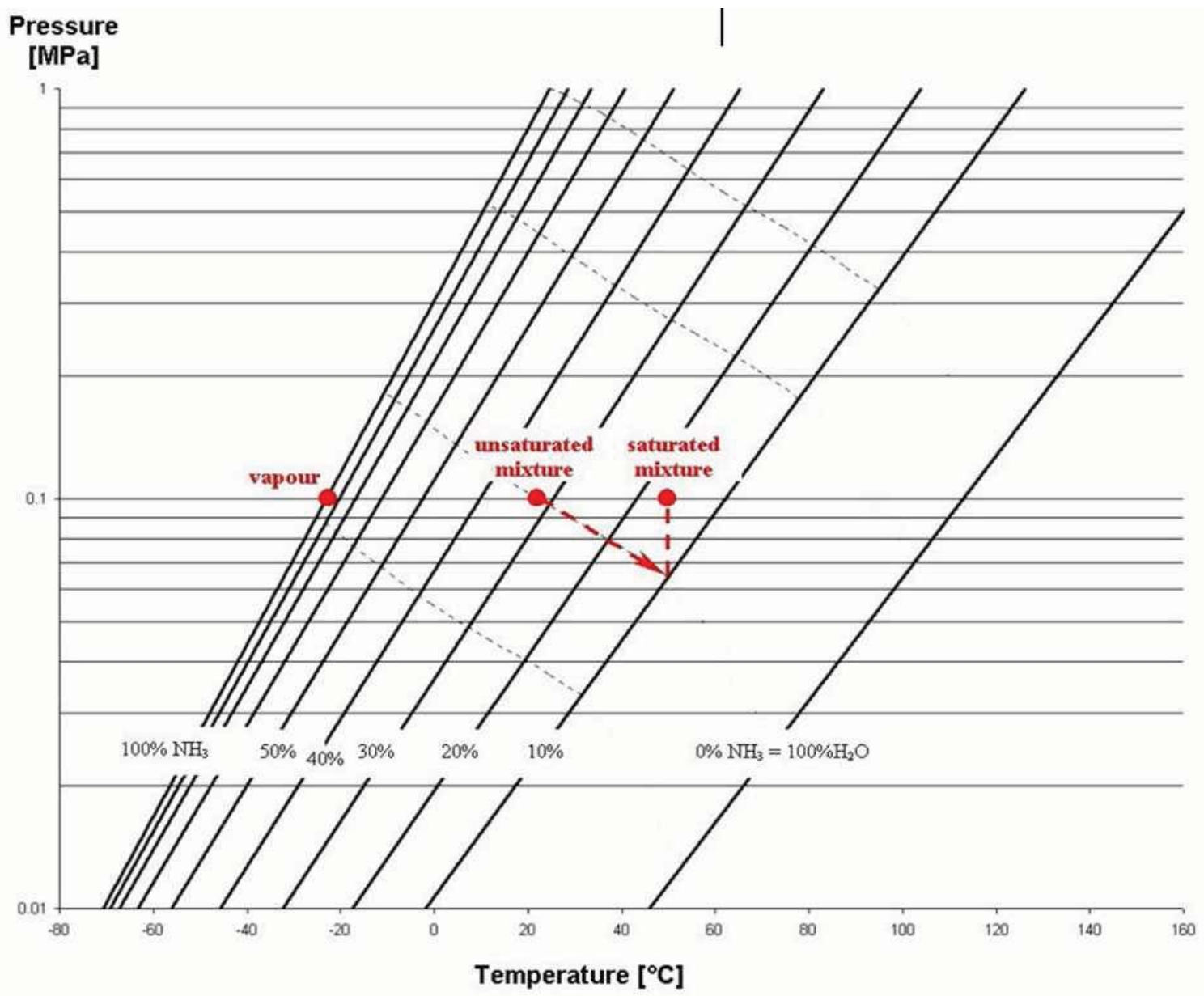

Figure 5 p-t-x diagram with the adiabatic absorption auxiliary lines

\section{Conclusions}

This paper introduces the new adiabatic absorption auxiliary lines in the $p-t-x$ diagram of ammonia-water system. These lines serve for fast determination of the saturated state of mixture only with knowledge of the unsaturated mixture parameters. The auxiliary lines assume absorption of refrigerant saturated vapor at constant pressure.

The paper introduces forming of the adiabatic absorption auxiliary lines with utilizing of equations for fast calculation of ammonia-water mixture properties. Iterative calculation process was used for determination of saturated state.

The new auxiliary lines help to estimate absorption temperatures during first suggestions of an absorption cycles. Correct determination of the absorption temperatures lead to designing of cycles with better absorption heat utilizing. The paper shows practical utilizing of the new auxiliary lines too.

Acknowledgements:

This work has been financially supported by the Czech Science Foundation under the Grant P101/10/1669 and Brno University of Technology, FSI under Grant BD13102011. 


\section{REFERENCES}

[1] Patek J., Klomfar J., 1995: Simple functions for fast calculations of selected thermodynamic properties of the ammonia-water system, Int. J. Refrigeration, 18(4), 228-234

[2] Tillner-Roth, R.,D. G. Friend, 1998: Survey and Assessment of Available Measurements on Thermodynamic Properties of the Mixtures, J. Phys. Chem. Ref. Data, 27(1), 45-61

[3] Sassen, C. L., R.A.C. van Kwartel, H.J. van der Kooi, J. de Swan Arons, 1990: Vapor - Liquid Equilibria for the System Ammonia + Water up to the Critical Region, j. Chem. Eng. Data, 35, 140-144 